\title{
Entre a lágrima e a transgressão: a ambiguidade do kitsch no projeto moderno da arte e da arquitetura
}

Between the tear and transgression: the kitsch ambiguity in modern art and architecture

Entre la lágrima y la transgresion:la ambigüedad del kitsch em lo projecto moderno del arte y arquitetura

Gerson Luís Trombetta*

\section{Resumo}

O artigo analisa o fenômeno kitsch sob dois aspectos: 1) o kitsch supre plenamente a necessidade estética de "ver e possuir", típica da sociedade industrial; 2) o kitsch, de outro modo, pode agregar memórias e experiências de vida. No espaço doméstico e nas composições informais da arquitetura desempenha o papel de "elemento transgressor" contra as estruturas funcionais do ambiente urbano.

Palavras-chave: Kitsch. História da arte. Arquitetura moderna. Sentimentalismo. Memória.
O processo de industrialização, a partir da segunda metade do século XIX, alterou significativamente o panorama estético do ocidente. Além de impulsionar a produção artística na direção de novas possibilidades formais e oferecer novos aparatos técnicos (como a fotografia e o cinema), tal processo ampliou o acesso aos bens culturais. $\mathrm{O}$ consumo de tais bens, antes restrito à aristocracia e a iniciados, expandiu-se como nunca. Dentre as consequências dessa democratização está o kitsch. Os novos receptores da sociedade industrial, tentando imitar o glamour da aristocracia, procuravam no produto falso, parecido e acessível, o mesmo "poder" do original. Para o consumidor, a sedução do kitsch se encontra nessa ilusão de comparti-

\footnotetext{
Doutor em Filosofia; professor do Programa de Pós-Graduação em História e dos cursos de graduação em Filosofia e Arquitetura da Universidade de Passo Fundo. E-mail: gersont@upf.br

Recebido em 25/03/2015 - Aprovado em 15/04/2015 http://dx.doi.org/10.5335/hdtv.15n.2.5651
} 
lhar os efeitos atraentes da arte, como um eco das suas promessas de felicidade.

Tendo esse quadro histórico como referência, este trabalho analisa o fenômeno kitsch com base em duas hipóteses: 1) o kitsch pode ser compreendido como um "efeito colateral" do projeto moderno nas artes e na arquitetura. Ao afastar-se dos padrões clássicos de beleza (mais próximos do gosto médio) e "desartificar-se" (o termo é de Adorno), o projeto moderno abriu um "flanco estético" que foi ocupado sistematicamente pelo kitsch. O kitsch, nesse particular, oferece fartas oportunidades para, como sugere Milan Kundera, "comoção e lágrimas"; 2) numa perspectiva distinta, não se deve ignorar a capacidade do "objeto kits$c h$ " de agregar memórias e experiências de vida. Por conta disso, de modo especial no espaço doméstico e nas composições informais da arquitetura, desempenha o papel de "elemento transgressor" contra a frieza das estruturas funcionais do ambiente urbano.

\section{Kitsch:aspectos etimológicos e históricos}

$\mathrm{O}$ advento da sociedade industrial transformou significativamente o panorama estético do ocidente. Além de impulsionar a produção artística na direção de novas possibilidades formais e oferecer novos aparatos técnicos (como a fotografia e o cinema), ampliou o acesso aos bens culturais. $\mathrm{O}$ consumo de tais bens, antes restrito à aristocracia e a iniciados, passou a ingressar na ordem do dia de um número cada vez maior de pessoas. Dentre os efeitos dessa saudável democratização está o kitsch, considerado, por parte de alguns intelectuais (GREEN-
BERG, 2001; KULKA, 1996; ECO, 1970), um subproduto estético. Os novos receptores, tentando imitar o glamour da aristocracia, procuravam no produto falso, parecido e acessível, o mesmo "poder" do original. Para o consumidor, a sedução do kitsch se encontra nessa ilusão de compartilhar os efeitos atraentes da arte, como um eco das suas promessas de felicidade.

O sentido etimológico do termo "kitsch" é incerto. Uma possibilidade é que tenha surgido do inglês sketch, literalmente "esboço", e tenha se consolidado no final do século XIX no comércio da arte, designando, ironicamente, os truques dos mercadores para desvalorizarem as obras que pretendiam adquirir. Para a maior parte dos estudiosos, entretanto, o termo provém do verbo alemão kitschen (CARCHIA; D'ANGELO, 2009 , p. 223), que significaria (na oralidade) algo como "recolher o lixo" ou, ainda, "fazer móveis novos com velhos" (MOLES, 1975, p. 10). A etimologia está ligada também à verkitschen, algo como "trapacear, receptar, vender alguma coisa em lugar do que havia sido combinado" (MOLES, 1975, p. 10) ou "maquiar móveis para que pareçam antigos" (ECO, 2007, p. 394).

Independente da diversidade de compreensões quanto à origem do termo, tanto críticos como defensores do kitsch modelaram uma imagem unitária do conceito, que foi se consolidando na passagem do século XIX para o XX. O kitsch passou a designar objetos ofertados para realização de experiências estéticas fáceis, e que não se definem pelo significado, mas pela liberdade e pelas emoções do sujeito. A estatuária ornamental, os souvenirs, as cópias de obras de arte 
clássicas, quinquilharias e bugigangas fabricadas em série para servir como enfeites de todo tipo são exemplos de tais objetos.

$\mathrm{O}$ kitsch, entendido enquanto estilo, é a expressão de um projeto que renuncia a qualquer pretensão de atender aos valores tradicionais da arte, como a verdade e a autenticidade. Em outra direção, substitui tais valores por critérios de sensibilidade individual, apostando na ficção, na citação e na reprodução em série. Um exemplo bastante claro da dinâmica do "estilo kitsch" está no consumo de objetos religiosos. Tais objetos (imagens, estatuetas, etc.) simulam algo que, simbolicamente, une o espectador a uma força transcendental, mas que, originariamente, saiu de um molde que deu forma a produtos suficientes para que outras centenas de milhares de pessoas comprassem a mesma experiência transcendental.

Se entendermos o kitsch numa acepção genérica como degradação da forma artística, podemos afirmar que, de algum modo, ele sempre existiu, constituindo uma história paralela à história da arte. Entretanto, a transformação do kitsch em um princípio estilístico ou mesmo de uma "atitude kitsch", como indica Greenberg (2001), corresponde a uma época de intenso desenvolvimento das técnicas de reprodução, evento que potencializou a circulação de objetos supostamente artísticos e modificou profundamente a forma de acesso às obras de arte.

\section{A"lágrima kitsch"}

A moda de colecionar aquários domésticos, na Inglaterra vitoriana, durante as décadas de 1850 e 1860, pode ser consi- derada, segundo Olalquiaga (2007), como um dos primeiros exemplos de cultura de massas. Nesse fenômeno, um objeto ou uma agrupação de objetos se torna um desejo de consumo tão obsessivo que, apesar de sua fabricação seriada e da sua multiplicidade, é experimentado como algo íntimo e pessoal. O que acontece nesse tipo de sucesso de consumo é algo constante nas relações com o kitsch, reconfigurando a aura misteriosa de autenticidade que ficara perdida no processo de industrialização. Os tais aquários ofereciam um cenário adaptável para os lugares vitorianos e garantiam o estímulo visual típico da cultura de massas.

Testemunha do desenvolvimento das técnicas de reprodução, a segunda metade do século XIX transformou o "inconsciente ótico" (OLALQUIAGA, 2007, p. 15) da cultura ocidental. A oferta generosa de objetos, além de baratear o acesso, originou uma sensibilidade específica, cuja base é a supremacia da visão e a posse acumulativa. Ainda que essa forma de sensibilidade tenha sido vivenciada nos séculos anteriores pelas classes aristocráticas, ${ }^{1}$ o que se consolida nesse momento é a democratização sem precedentes históricos da dinâmica "olhar e possuir". Isso elimina aquele "campo de força" ou "aura" que criava uma distância psicológica da arte, deixando-a muito mais próxima do sagrado do que da lógica do consumo. Como assinala Benjamin (1975), a qualidade principal de uma imagem que serve para o culto é ser inatingível. Devido a sua própria natureza, ela está sempre longínqua, por mais próxima fisicamente que possa estar. Pode-se aproximar de sua materialidade, mas sem alcançar o caráter longínquo que 
ela conserva a partir do momento em que aparece.

A arte, enquanto bem cultural, teve no culto a sua primeira razão de ser. A sua característica mais fundamental era a magia que incorporava, e seu poder estava mais na sua presença do que no fato de ser vista. Endereçada aos deuses, muitas vezes só os iniciados podiam acessá-la. À medida que a cultura se secularizou, aumentaram as ocasiões para a exposição da arte e seu valor de culto foi, gradativamente, substituído pelo valor de exibição, renunciando o seu pedestal de autenticidade e intangibilidade.

Como um fetiche, a autenticidade representa uma época em que a percepção das coisas era mais direta, sem a mediação do valor de troca e seu complicado sistema de equivalências. A singularidade, outro componente essencial do valor de culto, surpreendentemente, não saiu de cena com a proliferação das cópias. Mais que um simples objeto fácil de distinguir, como é o original em relação à cópia, a singularidade passou a assumir a forma de um sentimento ou percepção que pode ser provocada por um número considerável e diverso de experiências (OLALQUIAGA, 2007, p. 17). Como implica o próprio nome, a "singularidade" indica uma distinção de valor, anexando ao objeto um tipo específico de interação ou o que poderíamos chamar de "valor de experiência". Ou seja, a singularidade não é uma qualidade intrínseca ao objeto; é, sim, uma espécie de personalização do objeto na privacidade de cada ambiente pessoal, seja ele um álbum, uma casa, um jardim, uma estante ou uma porta de geladeira. Nesse caso, não faz diferença se existem milhares de cópias à venda daquelas miniaturas de gesso que enfeitam o jardim; a seleção e a composição dos cenários permitem aos consumidores estabelecer uma relação particular com os objetos, tornando-os singulares. Mesmo que sejam objetos ordinários e triviais, naquela composição são investidos de significados pessoais e valores sentimentais.

Ainda que pareça contraditório, a reprodução em massa de objetos decorativos contribuiu para afirmar a singularidade, a qualidade de "único entre todos". Permitiu também que o "colecionador" criasse relações dinâmicas com os objetos. Saindo da posição de passivo contemplador, pode agora compor os seus cenários, montar "mundos" que suscitem emoções suaves e acolhedoras, como se, com essa atitude, pudesse constituir uma "aura" que aqueles objetos abandonaram ao sair da linha de produção. A experiência com o objeto kitsch, assim, não exige do expectador um espírito atento e esforçado ou pré-conhecimentos da história da arte. Não reivindica mais do que sua capacidade emocional. Vista dessa forma, a relação com o objeto kitsch é a ocasião para o que Solomon (1991) denominou de sentimentalismo (sentimentality).

Conectado a uma experiência suave, o kitsch faz nascer o que Kundera chamou de um tipo específico de "lágrima":

O kitsch faz nascer, uma após outra, duas lágrimas de emoção. A primeira lágrima diz: como é bonito crianças correndo no gramado! A segunda lágrima diz: como é bonito ficar emocionado, junto com toda humanidade, diante de crianças correndo no gramado! Somente essa segunda lágrima faz com que o kitsch seja o kitsch (1985, p. 263). 
Na contramão dessa segunda lágrima estão os desafios assumidos pela arte moderna, muito mais ligados a emoções complexas (como o sublime) $)^{2}$ e a prerrogativas conceituais. Como alternativa para permanecer no mundo e resistir à apropriação do consumo fácil e dos processos de massificação, a arte moderna inaugurou experiências estéticas que, muitas vezes, contrariam o interesse dos sentidos e nossas expectativas de beleza e prazer. Adorno (1988) denominou esse processo de "desartificação" (Entkustung der Kunst), alternativa histórica encontrada pela arte e pelos artistas para resistir à lógica fetichista da indústria cultural. O objeto artístico (moderno), pela sua inesgotabilidade e inacessibilidade, convida o indivíduo a experimentar a negação das suas expectativas de prazer. A "lágrima", na experiência com a arte moderna, nasce do encontro do sujeito com o seu próprio limite, no encontro com a crítica radical à tendência subjetiva de requerer, dos objetos, constantes respostas prazerosas. Isso leva a crer que a batalha entre o kitsch e a vanguarda (GREENBERG, 2001) não é apenas de objetos, de formas e de técnicas; é, sim, uma batalha travada no campo das sensações.

\section{0 kitsch como transgressão}

Quando observamos a quantidade de cenários kitsch espalhados pelas cidades e o esforço e o tempo que seus proprietários gastam para garantir sua manutenção, nos parece precipitado simplesmente identificá-lo com uma questão de "mau gosto". Para Solomon (1991), reduzir o kitsch ao mau gosto e a uma experiência superficial tem a ver com uma compreensão negativa da noção de sentimentalismo (sentimentality). Solomon (1991) expõe cinco críticas normalmente feitas quando identificamos sentimentalismo e kitsch: a) o kitsch produz como efeito expressões emocionais ingênuas e imaturas. Como, por exemplo, quando consideramos o sapinho sorridente, feito de gesso e tinta, que enfeita o jardim, como "fofinho" ou "meigo"; b) o kitsch propositalmente manipula nossas emoções limitando nossa capacidade de visitarmos experiências estéticas mais complexas; c) o kitsch e o sentimentalismo evocam "falsas emoções", como um estimulante artificial quando a coisa real não está disponível. É o caso dos objetos kitsch com apelo sexual que remetem a um desejo que não podem realizar; ${ }^{3} \mathrm{~d}$ ) o kitsch evoca emoç̃os "baratas" e "fáceis". $\mathrm{O}$ "barato" do kitsch é um termo que designa, por tabela, certas restrições econômicas para o acesso à arte autêntica e seus efeitos emocionais; e) o kitsch e o sentimentalismo distorcem nossas percepções e interferem no pensamento racional e na compreensão adequada do mundo. O kitsch distorceria a realidade para que o indivíduo obtenha o pretexto que necessita para se entregar a qualquer sentimento.

A questão a ser posta, então, é se tais críticas são procedentes ou se o kitsch, pelo contrário, é um depositário importante de anseios, referências de identidade e conexões com a coletividade. Nossa posição é que, apesar de o kitsch designar, na sua origem, uma experiência estética reduzida, seria inadequado desconsiderar a sua força de atração, principalmente quando procuramos entender o modo como o gosto popular 
estrutura os espaços cotidianos de moradia e de convivência. A hipótese é que o kitsch aparece como marca de identidade, como uma estratégia para estabelecer contrastes em relação ao ambiente urbano, elaborando um ambiente agradável e belo segundo as percepções do próprio usuário. $\mathrm{O}$ kitsch, apesar de todos os interesses econômicos que orbitam ao seu redor, pode abrir clareiras para compreender as relações que o ser humano constrói com o espaço onde vive. Longe das pranchetas dos arquitetos, as composições kitsch guardam uma profunda honestidade na expressão da identidade do seu criador, produzindo garantias de afirmação social. Compreendido assim, o kitsch posiciona-se como elemento de transgressão, de modo especial contra os princípios da arquitetura funcionalista.

O ideário funcionalista, na arquitetura, inspira-se na frase popularizada pelo arquiteto americano Louis Sullivan: "a forma segue a função". O arquiteto franco-suíço Le Corbusier, um dos mentores desse movimento estético, em Por uma arquitetura, apresenta uma espécie de carta de princípios de como deveria ser uma arquitetura harmonizada com os tempos modernos. Como um sinal dos tempos, segundo ele, a arquitetura começou a desprezar os palácios e se ocupar da casa do homem comum - foi o novo espírito do pós-guerra. Isso se percebe, principalmente, quando, ao invés de ostentação, prioriza-se a eficiência, a precisão, a rapidez e a funcionalidade. Encontrar "a necessidade-tipo, a função-tipo, a emoção-tipo" (LE CORBUSIER, 2002, p. XVII), eis a função do arquiteto. Para cumprir a função de subsidiar as necessidades do homem, a arquitetu- ra deveria se alinhar às mudanças ocorridas ao longo da Revolução Industrial e deixar para trás os "enormes pedaços de nossa vestimenta sentimental de outrora" (LE CORBUSIER, 2002, p. XXV). Para acompanhar o homem moderno, a casa moderna não veste luxo: deve ser a casa-instrumento, a máquina de morar. A emoção que acompanha a arquitetura deveria ser a do encontro com uma grandeza de intenção, com uma planta traçada por órgãos vivos, com disposições pensadas a partir das suas relações com o conjunto. O projeto funcionalista visa, sob esse ponto de vista, afastar a arquitetura de qualquer sentimentalismo (sentimentality).

Já que os instrumentos do homem marcam as etapas do desenvolvimento da civilização, dos acúmulos de aperfeiçoamento, a casa, como primeiro instrumento forjado pelo homem graças ao seu instinto de se abrigar, deve, da mesma forma, deixar para trás as formas obsoletas de arquitetura. Le Corbusier considera que, no início do século $X X$, a arquitetura sofria uma penosa regressão enquanto a engenharia gozava de pleno florescimento. A função do arquiteto, de exprimir a beleza, era desempenhada pelo engenheiro, por meio do cálculo e da lei da economia. A arquitetura não acompanhou as exigências desse novo homem industrial. O novo homem pós-revolução industrial tem suas necessidades sensíveis equivalentes à forma de pensar do engenheiro: útil e ativa. Essas deveriam ser as diretrizes da casa moderna.

O homem moderno, para o arquiteto citado, é aquele que vive em um ambiente sem "objetos inúteis" e "ninharias ridículas", e prefere o conforto de um ambiente 
funcional como aquele que encontra no seu espaço de trabalho. Aliás, "via-se bem que eles eram mais felizes na fábrica ou em seu banco", diz ele em comparação com o conforto do ambiente residencial fora do padrão moderno. Isso porque a figuração e a "estória" distraem, e a arte moderna fez bem em descartá-las: o espírito moderno se afastou do excesso e se fechou naquilo que faz simplesmente meditar, como se vê explicitamente em uma pintura de Mondrian.

$\mathrm{Na}$ visão funcionalista, uma casa deveria ser uma "máquina para morar" (LE CORBUSIER, 2002, p. 65) e a arquitetura deveria se espelhar no inventor do avião. A lição a ser extraída dessa invenção é que voar artificialmente não deveria se basear na imitação do movimento de uma libélula ou de um pássaro. O avião é uma "máquina para voar", desenvolvida a partir da colocação de um problema preciso e de uma busca de solução a partir de suas demandas internas. Pensar um avião é pensar uma "máquina para voar" e, como tal, pensar um conjunto de coisas absolutamente necessárias para que o ato de voar aconteça; da mesma forma, implica em descartar tudo aquilo que atrapalha a realização de tal objetivo:

$\mathrm{O}$ avião nos mostra que um problema bem colocado encontra sua solução. [...] Inventar uma máquina para voar sem lembranças concedidas a quem quer que seja de estranho à pura mecânica, isto é, buscar um plano sustentador e uma propulsão era colocar corretamente o problema; em menos de dez anos todo mundo podia voar (LE CORBUSIER, 2002, p. 75).

Uma casa deveria funcionar com essa mesma lógica. Seu papel, segundo o próprio Le Corbusier (2002, p. 75), deve ser: "um abrigo contra o calor, o frio, a chuva, os ladrões e os indiscretos". Deve também ser um receptáculo adequado de luz e de sol e prever em seu interior espaços para a vida íntima, além de acomodar os equipamentos destinados à cozinha e ao trabalho. Qualquer enfeite ou outro tipo de objeto seria desnecessário e corromperia não só a funcionalidade da casa como a sua beleza. A recomendação era que as casas do futuro fossem ascéticas e limpas, disciplinadas, organizadas e econômicas. Isso viabilizaria a vivência das emoções apropriadas da arquitetura, algo totalmente distinto dos sentimentalismos do kitsch. A resistência de Le Corbusier por qualquer espécie de decoração era tanta que chegava a zombar de Roma, a "cidade dos horrores", "a maldição dos semianalfabetos", uma verdadeira corrupção da verdadeira arquitetura "por conta da profanação de princípios funcionais com o excesso de detalhes barrocos, pinturas murais e estatuaria" (DE BOTTON, 2007, p. 56).

Examinado sob o ponto de vista dos princípios da arquitetura funcionalista, o kitsch é um verdadeiro "escândalo estético". $\mathrm{O}$ kitsch poderia ser considerado como o contraponto, como o "outro lado" da estética funcionalista. Seus exageros, suas composições saturadas, seu colorido, as dificuldades de sua manutenção e, principalmente, sua inadequação à ideia de "máquina para morar" fazem do kitsch algo a ser programaticamente evitado num contexto em que a "função" deve ser a protagonista. Um objeto kitsch numa casa equivaleria, na lógica de Le Corbusier, a instalar uma estátua de bronze no interior de um aeroplano; ou seja, um capricho que colocaria em risco o propó- 
sito do aeroplano e, por decorrência, a própria vida do piloto.

A complexidade da experiência humana no mundo contraria em grande medida as convicções funcionalistas. Para Moles (1975), somos habitantes-construtores, personalizamos nossos espaços de acordo com nossa história, nossas nostalgias, nossas memórias, nossos desejos e nossos sonhos. Os cenários que edificamos têm funções participativas e não exclusivamente contemplativas. Por intermédio deles suprimos as necessidades de bem-estar, buscamos algo além da simples moradia, do simples abrigo ou receptáculo de equipamentos. O que o habitante-construtor faz ao personalizar seu espaço íntimo é projetar sua visão de mundo.

O kitsch, na relação com o ideário funcionalista, assume um papel transgressor na medida em que se instala nos ambientes construídos quando o arquiteto "dá as costas". Os cenários kitsch montados nos exteriores e interiores das casas, com suas composições saturadas, bricolagem, objetos imitando elementos naturais (animais e plantas), uso de cores chamativas, exageros, mosaicos e referências religiosas realizam o propósito de criar "zonas de aconchego", tornando o clima da casa mais divertido e acolhedor. Esse é um recurso para eliminar ou, no mínimo, disfarçar a frieza dos aspectos mais funcionais da construção, dando à casa uma personalidade própria. É como se o kitsch fosse um manifesto eloquente contra o universalismo frio do funcionalismo. Os objetos kitsch que se acumulam nas casas são transgressores por desafiarem o cinza urbano e o ascetismo das fábricas e do asfalto. Como aglutinadores de memórias decantadas e "sentimentalismos" compõem aquele que seja o aspecto mais fundamental do "morar".

Se os movimentos de vanguarda e as teses de Le Corbusier abrem caminho para conceitos que ousam contrariar os comuns acordos, há também de se notar que há movimentos de retaguarda, que não existem senão em um acomodamento contraposto à inovação. $\mathrm{O}$ kitsch não pede tempo para ser experimentado, como o faz a arte de vanguarda. O kitsch só pede algum dinheiro, e não muito, porque foi justamente esta acessibilidade que favoreceu a dissipação daquilo que antes era arte e agora virou embelezamento, "aquele tipo de beleza que gostaríamos de ver circundando nossa vida diária" (CALINESCU, 1999, p. 219).

O kitsch é um agradável escape às expectativas artificiais da vida quotidiana moderna. Como todo escape, é uma fuga; e, como toda fuga, é uma transgressão. É uma resposta possível e extravagante ao difundido sentimento moderno de vácuo espiritual. Como sugere Calinescu,

[...] ele preenche o tempo vazio de ócio com "alegria" ou "excitação" e ele "alucina" - se for permitido usar este verbo transitivamente - espaços vazios com um sortido infinitamente variegado de "maravilhosas" aparências (1999, p. 220).

A casa é o lugar perfeito para que o aspecto transgressor do kitsch se manifeste. É ela que reúne os aspectos mais fundamentais para que o indivíduo, como garantia de sobrevivência emocional, realize a personalização do espaço. Impregnando-o com marcas pessoais de memórias afetivas, de objetos "auratizados" por lembranças e, por 
que não, sentimentalismos, o morador pode, finalmente, tomar posse do seu lugar e de si mesmo. O kitsch transgride os ditames de uma vida funcional voltada exclusivamente para o trabalho; transgride esteticamente na medida em que é criação e/ou utilização inesperada de algum elemento; transgride pela impureza e pela ludicidade; transgride por brincar despretensiosa e escancaradamente com o falso; transgride ao violar a homogeneidade dos padrões de construção e ao garantir a singularidade daquele espaço e daquela experiência histórica.

\section{Abstract}

The study analyzes the kitsch phenomenon in two respects: 1) the kitsch fully meets the aesthetic need to "see and own", something that is typical of the industrial society; 2) moreover, kitsch can join in itself memories and life experiences. In the home and in informal architecture designs, it plays the role of "transgressive element" compared to the functional structures of the urban environment.

Keywords: Kitsch. Art history. Modern architecture. Sentimentality. Memory.

\section{Resumen}

El artículo analiza el fenómeno kitsch en dos aspectos: 1) El kitsch satisface plenamente la necesidad estética de "ver y poseer", típica de la sociedad industrial; 2) El kitsch, de otro modo, puede agregar recuerdos y experiencias de vida. En el espacio doméstico y en las compo- siciones informales de la arquitectura, desempeña el papel de "elemento transgresor" contra las estructuras funcionales del entorno urbano.

Palavras clave: Kitsch. Historia del arte. Arquitectura moderna. Sentimentalismo. Memoria.

\section{Notas}

1 Sobre a construção de uma sensibilidade baseada na dinâmica "olhar e possuir", vale a pena consultar o trabalho de Berger (1999, p. 91), de modo especial a sua análise do quadro "Os Embaixadores" (1533), do pintor alemão Hans Holbein.

2 Sobre a configuração das experiências estéticas incentivadas pela arte no século $X X$, remetemos ao nosso recente livro Harmonia e ruptura: a Crítica da faculdade do juízo e os rumos da arte contemporânea (TROMBETTA, 2015). Nele, buscamos sustentar que as categorias estéticas tradicionais como a beleza, a ordem e o prazer subjetivo já não são suficientes para explicar os efeitos da arte no indivíduo. Tais efeitos ficam melhor compreendidos a partir da noção de sublime.

3 Exemplos de objetos kitsch com apelo sexual podem ser encontrados em profusão no clássico $L a-$ ranja Mecânica (1971), de Stanley Kubrick.

\section{Referências}

ADORNO, Theodor. Teoria estética. Lisboa: Martins Fontes, 1988.

BENJAMIN, Walter. A obra de arte na época de suas técnicas de reprodução. São Paulo: Abril Cultural, 1975. (Os Pensadores).

BERGER, John. Modos de ver. Rio de Janeiro: Rocco, 1999.

CALINESCU, Matei. As cinco faces da modernidade: modernismo, vanguarda, decadência, kitsch, pós-modernismo. Lisboa: Vega, 1999.

CARCHIA, Gianni; D'ANGELO, Paolo. Dicionário de Estética. Lisboa: Edições 70, 2009. 
DE BOTTON, Alan. A arquitetura da felicidade. Rio de Janeiro: Rocco, 2007.

GREENBERG, Clement. Vanguarda e kitsch. In: FERREIRA, Glória; COTRIM, Cecília. Clement Greenberg e o debate crítico. Rio de Janeiro: Jorge Zahar, 2001. p. 27-43.

MOLES, Abraham. O kitsch. 2. ed. São Paulo: Perspectiva, 1975. (Debates).

ECO, Umberto. Apocalípticos e integrados. São Paulo: Perspectiva, 1970. (Debates). . (Org). História da feiúra. Rio de Janeiro: Record, 2007.

KULKA, Tomás. Kitsch and art. Pennsylvania: The Pennsylvania State Press, 1996.

KUNDERA, Milan. A insustentável leveza do ser. 3. ed. Rio de Janeiro: Nova Fronteira, 1985.

LE CORBUSIER. Por uma arquitetura. 6. ed. São Paulo: Perspectiva, 2002.

OLALQUIAGA, Celeste. El reino artificial: sobre la experiência kitsch. Barcelona: Editorial Gustavo Gili, 2007.

SOLOMON, Robert. On kitsch and sentimentality. The Journal of Aesthetic and Art Criticism, v. 49, n. 1, p. 1-14, Winter 1991.

TROMBETTA, Gerson Luís. Harmonia e ruptura: a Crítica da faculdade do juízo e os rumos da arte contemporânea. Passo Fundo: UPF Editora, 2015. 